\title{
Effects of Activating Chemicals on the Adsorption Capacity of Activated Carbons Prepared from Palm Kernel Shells.
}

\author{
Babayemi, Akinpelu.K \\ Department of Chemical Engineering, Anambra State University, Nigeria.
}

\begin{abstract}
This work studies the effects of $\mathrm{H}_{2} \mathrm{SO}_{4}, \mathrm{Al}_{2}\left(\mathrm{SO}_{4}\right)_{3}, \mathrm{NH}_{4} \mathrm{Cl}$ as activating chemicals on the adsorption capacity of activated Palm Kernel Shells (PKN). Proximate analysis was carried out on PKN. Batch mode experiments were employed to study the effects of adsorbent dosage and contact time on PKN for the removal of phosphorus from wastewater. Adsorption equilibrium data were described by Langmuir, Freundlick and Temkin Isotherms using non-linear regression analysis. Statistical modeling via Central Composite Design (CCD) for process optimization was carried out. From the obtained results, the activating chemicals can be arranged in order of increasing effectiveness thus: $\mathrm{NH}_{4}<\mathrm{Al}_{2}\left(\mathrm{SO}_{4}\right)_{3}<\mathrm{H}_{2} \mathrm{SO}_{4}$. The optimization presents $\mathrm{H}_{2} \mathrm{SO}_{4}$., among others, the best activating chemicals with a performance of $93.54 \%$. The adsorption data were best described by Freundlick Isotherm model.
\end{abstract}

Keywords: activating chemicals, phosphorus, adsorption, adsorbent, activated carbon.

\section{Introduction}

Environmental degradation caused by human activities has become a serious concern to many researchers worldwide. Such activities include industrial operations particularly in chemical, agricultural, textiles mining and petrochemical industries. In the course of these operations, a lot of hazardous wastes are generated and indiscriminately discharged into surface waters. These wastes contain heavy metals organic and inorganic substances such as Nickel, Chromium, Lead, Zinc, Arsenic, Cadmium, Phosphate, Chloride and Nitrate to mention but few $[1,2,3]$. The presence of these contaminants in the receiving waters might cause health hazards to a large segment of the population in addition to loss of many aquatic animals.Many researchers $[4,5,6,7,8,9,10]$ have done a great work in removing heavy metals from wastewaters, however it is imperative to find an effective method to equally remove nutrients particularly phosphorus from wastewater because of its dangerous effects on the water bodies. One of the resulting effects is eutrophication. It is described as the excessive growth of algae, which leads to the depletion of dissolved oxygen in water and consequently death and reduction in aquatic fish and other animal population [11]. Against this background, an activated carbon prepared from palm kernel shells has been adopted for the removal of phosphorus from wastewater through the process of adsorption. In a further search for highly effective activated carbons, chemical activation was introduced using three different activating chemicals and a comparism was made among them to know which of them would enhance the performance of the adsorbents.

\section{Materials And Methods}

Palm Kernel Shells were obtained from Ihiala, Anambra State. The shells were washed of the accompanying dirts and thereafter, dried in an oven at $110^{\circ} \mathrm{C}$ for $24 \mathrm{hrs}$. The dried sample was then carbonized in a muffle furnace at a temperature of $800^{\circ} \mathrm{C}$ for $3 \mathrm{hrs}$. The carbonized material was allowed to cool to room temperature, ground and sieved using $0.2 \mathrm{~mm}$ mesh. $20 \mathrm{~g}$ of the sieved fractions was added into each of three separate beakers containing $200 \mathrm{ml} 1 \mathrm{M} \mathrm{H}_{2} \mathrm{SO}_{4}, 1 \mathrm{M} \mathrm{Al}_{2}(\mathrm{SO} 4)_{3}$ and $1 \mathrm{M} \mathrm{NH}_{4} \mathrm{Cl}$ respectively for $12 \mathrm{hrs}$. impregnating the carbonized material in the activating chemicals was to open up and activate the pore surfaces of the carbon for effective adsorption. The impregnated sample was washed with de-ionized water until $\mathrm{pH} 7$, filtered and dried in an oven at $1110^{\circ} \mathrm{C}$ for $24 \mathrm{hrs}$ before being packed in an air tight sample bags for use.

Proximate analysis was carried out on the activated PKN to determine the \% weight loss, bulk density $\left(\mathrm{g} / \mathrm{cm}^{3}\right)$, $\%$ moisture content, $\%$ volatile matter, $\%$ fixed carbon and iodine number using standard method $[12,13]$. Surface area of the PKN was determined using Sear's Method [3,14].

\section{Batch Adsorption Experiment}

The effluent used was synthesized using phosphate rock obtained from Federal Superphosphate Fertilizer Company, Kaduna, Nigeria. The initial $\mathrm{pH}$ of the effluent was measured with a digital $\mathrm{pH}$ meter and recorded. 1.0g of the PKN activated with $\mathrm{H}_{2} \mathrm{SO}_{4}$ was added into the beaker containing $100 \mathrm{ml}$ of the prepared effluent and placed on a magnetic stirrer. Stirring was done at $30 \mathrm{mins}, 60 \mathrm{mins}, 120 \mathrm{mins}, 180 \mathrm{mins}, 240 \mathrm{mins}$ and 300 mins respectively. Upon the completion of each stirring period, the solution was filtered and the residual concentration of the filtrate was determined using UV-spectrophotometer set at a wavelength of $650 \mathrm{~nm}$ [11]. The same procedure was repeated for $2.0 \mathrm{~g}, 3.0 \mathrm{~g}, 4.0 \mathrm{~g}$ and $5.0 \mathrm{~g}$ of the adsorbent. 


\section{Results And Discussion}

The characterization results of PKN are presented in Table 1. It was evident from the obtained results that activating chemicals have effects on the surface area of the adsorbents. The same PKN exhibiting different surface area as a result of different activating chemicals used. The higher surface area provided by the acid treated PKN is due to the significant removal of organic by-products and minerals present in the activated carbon surface during activation $[11,15]$.

\section{Effects of dosage and contact time}

The profiles of removal efficiency (E\%) as a function of time at varied dosage of PKN activated with $\mathrm{H}_{2} \mathrm{SO}_{4}, \mathrm{Al}_{2}\left(\mathrm{SO}_{4}\right)_{3}$ and $\mathrm{NH}_{4} \mathrm{Cl}$ respectively are presented in Fig.1-3. E\% for the three activating chemicals increased with time as well as with increasing dosages. However, it is worth noting that at the same contact time, the adsorption capacities of the various activated PKN differ. The contact time of 120 mins, dosage of $50 \mathrm{~g} / \mathrm{l}, \mathrm{E} \%=96.99$ for $\mathrm{H}_{2} \mathrm{SO}_{4}$ as presented in Fig. 1. Also, at the same contact time and dosage, $\mathrm{E} \%$ for $\mathrm{Al}_{2}\left(\mathrm{SO}_{4}\right)_{3}$ and $\mathrm{NH}_{4} \mathrm{Cl}$ are 96.41 and 95.82 respectively. This is an indication that, types of activating chemicals used for modification of adsorbent's surface play very important roles in enhancing their adsorption capacities.

\section{Non-Linear Isotherm Model}

The equilibrium concentration data and the amount of adsorption were fitted to Freundlick, Langmuir and Temkin Isotherms using the non-linear regression analysis of the curve fitting tool box of MATLAB 7.0. The numerical fit results are graphically presented in Fig. 4-6. It was evident from the results of the analysis that, the equilibrium data were best described by Freundlick Isotherm model.

\section{Statistical Modeling and Optimization}

The model fit for the adsorption process after deleting the insignificant interacting factors, is given as: $\mathrm{Y}_{\mathrm{H} 2 \mathrm{SO} 4}=105.6181-0502 \mathrm{x}_{1}-28.3824 \mathrm{x}_{2}-0.0002 \mathrm{x}_{1} \mathrm{x}_{2}+0.00024 \mathrm{x}_{1}{ }^{2}+3.4835 \mathrm{x}_{2}^{2}$ $\mathrm{Y}_{\mathrm{Al} 2(\mathrm{SO} 4) 3}=107.9945-0.0587 \mathrm{x}_{1}-26.7049 \mathrm{x}_{2}-0.0019 \mathrm{x}_{1} \mathrm{x}_{2}+0.000033 \mathrm{x}_{1}{ }^{2}+3.3631 \mathrm{x}_{2}^{2}$ $\mathrm{Y}_{\mathrm{NH} 4 \mathrm{Cl}}=111.5956-0.0687 \mathrm{x}_{1}-25.8122 \mathrm{x}_{2}-0.0031 \mathrm{x}_{1} \mathrm{x}_{2}+0.000043 \mathrm{x}_{1}{ }^{2}+3.3870 \mathrm{x}_{2}{ }^{2}$

Where $\mathrm{Y}_{\mathrm{H} 2 \mathrm{SO} 4}, \mathrm{Y}_{\mathrm{Al} 2(\mathrm{SO} 4) 3}, \mathrm{Y}_{\mathrm{NH} 4 \mathrm{Cl}}$ are the dependent variables representing the amount of phosphorus adsorbed per gram of $\mathrm{PKN}$ activated with $\mathrm{H}_{2} \mathrm{SO}_{4}, \mathrm{Al}_{2}\left(\mathrm{SO}_{4}\right)_{3}$ and $\mathrm{NH}_{4} \mathrm{Cl}$ respectively. $\mathrm{x}_{1}, \mathrm{x}_{2}$ are the independent variables representing dosage and contact time respectively.

In all cases of the activated PKN, the model accuracy is validated by the values of $R^{2}>0.9$ and Adj. $R^{2}>0.9$ and the closeness of the predicted values to the actual experimental values as presented in Fig. $7-9$.

The main attribute to effective performance of PKN as adsorbent is its residence time. This agrees with the surface plots that show a quadratic profile with time as presented in Fig. $10-12$. The optimization of surface response model reveals that $\mathrm{PKN}\left(\mathrm{H}_{2} \mathrm{SO}_{4}\right)$ reduced the phosphorus concentration in the effluent from $373 \mathrm{mg} / \mathrm{l}$ to $24.1038 \mathrm{mg} / \mathrm{l}$, a performance of $93.54 \%$, PKN $\left(\mathrm{Al}_{2}\left(\mathrm{SO}_{4}\right)_{3}\right)$ reduced the phosphorus contaminants from $373 \mathrm{mg} / \mathrm{l}$ to $29.1313 \mathrm{mg} / \mathrm{l}$ giving a performance of $92.19 \%$ while $\mathrm{PKN}\left(\mathrm{NH}_{4} \mathrm{Cl}\right)$, has the least performance of $90.47 \%$. Activating chemicals used in this research work can thus, be arranged in the order of decreasing effectiveness: $\mathrm{H}_{2} \mathrm{SO}_{4}>\mathrm{Al}_{2}\left(\mathrm{SO}_{4}\right)_{3}>\mathrm{NH}_{4} \mathrm{Cl}$

\section{Conclusion}

Among the three activating chemicals considered in this study, $\mathrm{H}_{2} \mathrm{SO}_{4}$ was found the most effective. PKN activated with $\mathrm{H}_{2} \mathrm{SO}$ has a performance of $93.54 \%$ while $\mathrm{NH}_{4} \mathrm{Cl}$ was the least effective. The adsorption data were best described by Freundlick Isotherm Model.

Above all, this work has revealed that Palm Kernel Shell being an agricultural waste could be converted to useful and efficient adsorbent through the use of activating chemicals, particularly $\mathrm{H}_{2} \mathrm{SO}_{4}$.

\section{Reference}

[1]. Dimple Lakherwal (2014). Adsorption of Heavy Metals: A review. International Journal of Environmental Research and Development. 4(1), 41-48.

[2]. Joseph T. Nwabanne and Philomena K. Igbokwe (2011) Copper (II) uptake by Adsorption using Palmyra Palm Nut. Advances in Applied Science Research.2(6). 166 - 175.

[3]. Babayemi A.K, Onukwuli O.D (2016). Adsorption Isotherms, Thermodynamics and Statistical Modeling of Phosphate Removal from Aqueous Solution by Locally Prepared Bio-Sorbent. Journal of Applied Chemistry (IOSR - JAC). 9(6) ver.II.46-50.

[4]. Nwabanne J.T. (2010). Adsorption and Kinetic Modeling of Heavy Metals Uptake from Wastewater Effluents. Ph.D thesis, Nnamdi Azikiwe University, Nigeria.

[5]. Kafia M; Shareef Surchi (2011). Agricultural Wastes as Low Cost Adsorbents for Pb Removal: Kinetics, Equilibrium and Thermodynamics. International Journal of Chemistry. Canadian Center of Science and Education. 3(3), p103.

[6]. Ugwekar, RP, Lakhawal (2012). Recovery of Heavy Metal by Adsorption using Peanut Hull. International Journal of Advanced Engineering Technology. 3(3) pp. $39-43$.

[7]. Kermit Wilson, Hong Young, Chung W. Seo, Wayne E. Marshall (2005). Select Metal Adsorption by Activated Carbon made from Peanut Shells. Bio-resource Technology. 97, 2266 - 2270. 
[8]. Tangjuank .S, Insuk.N, Udeye.V, Tontrakoon.J (2009). Chromium (III) Sorption from Aqueous Solutions Using Activated Carbon Prepared from Cashew Nut Shells International Journal Of Physical Sciences.4 (8) Pp 412-417.

[9]. Uttam Singh, Rajesh Kumar Kaushal (2013). Treatment of Wastewater with Low Cost Adsorbent - A Review. International Journal of Technical and Non-Technical Research. 4(3), 33-41.

[10]. Opeolu, B.O and Fatoki, O.S (2012). Dynamics of zinc sorption from aqueous matrices using plantain (Musa sp) Peel Biomass. African Journal of Biotechnology. 11 (68) pp $13194-13201$.

[11]. Babayemi A.K. (2014). Removal of Phosphorus from Industrial and Synthetic Effluent using Non-Conventional Coag-flocculation and Adsorption. Ph.D thesis, Nnamdi Azikiwe University, Nigeria.

[12]. ASTM (1994). American Standard for Testing Materials, U.S.A

[13]. AOAC(1989). "Official methods of Analysis" Association of official Analytical Chemists. Washington D.C, 14 ${ }^{\text {th }}$ Edition

[14]. Alzaydien A.S (2009). Adsorption of Methylene Blue from Aqueous Solution onto a Low-Cost Natural Jordanian Tripoli. Am. J. Env. Sci. 6(6), $1047-1058$.

[15]. Menkiti M.C(2010). Sequential treatment of Coal Washery and Brewery Effluents by Biocoag-Flocculation and Activated Carbon Adsorption. Ph.D Thesis, Nnamdi Azikiwe University, Nigeria.

Table 1: Characterization Results of PKN

\begin{tabular}{|l|l|l|l|}
\hline \multirow{2}{*}{ Parameter } & \multicolumn{3}{|l|}{ Activating chemicals } \\
\cline { 2 - 4 } & $\mathbf{H}_{\mathbf{2}} \mathbf{S O}_{\mathbf{4}}$ & $\mathbf{A l}_{\mathbf{2}}\left(\mathbf{S O}_{\mathbf{4}}\right)_{\mathbf{3}}$ & $\mathbf{N H}_{\mathbf{4}} \mathbf{C l}$ \\
\hline$\%$ weight loss & 35.38 & 38.07 & 44.79 \\
\hline Bulk density $\left(\mathrm{g} / \mathrm{cm}^{3}\right)$ & 0.48 & 0.55 & 0.58 \\
\hline$\%$ Ash content & 6.33 & 5.38 & 5.00 \\
\hline Iodine number $(\mathrm{mg} / \mathrm{g})$ & 558.06 & 474.35 & 440.86 \\
\hline Volatile matter $(\%)$ & 17.74 & 18.37 & 18.94 \\
\hline Moisture content $(\%)$ & 5.81 & 5.98 & 6.01 \\
\hline Fixed carbon & 75.28 & 63.99 & 59.47 \\
\hline Surface area & 635.73 & 569.37 & 529.25 \\
\hline
\end{tabular}

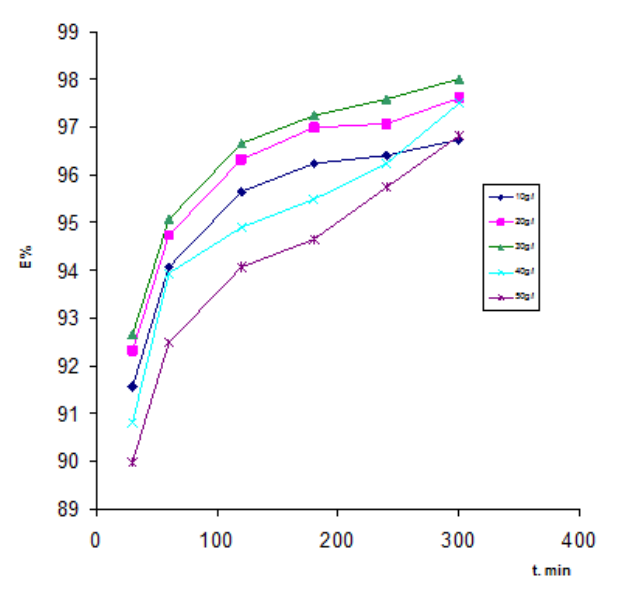

Fig. 1: Removal efficiency of $\mathrm{PKN}$ activated with $\mathrm{H}_{2} \mathrm{SO}_{4}$ at different adsorbent concentration

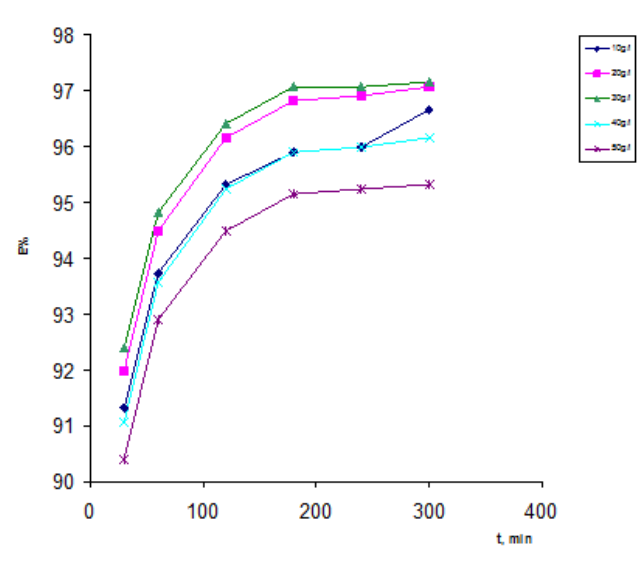

Fig. 2: Removal efficiency of PKN activated with $\mathrm{Al}_{2}\left(\mathrm{SO}_{4}\right)_{3}$ at different adsorbent concentration

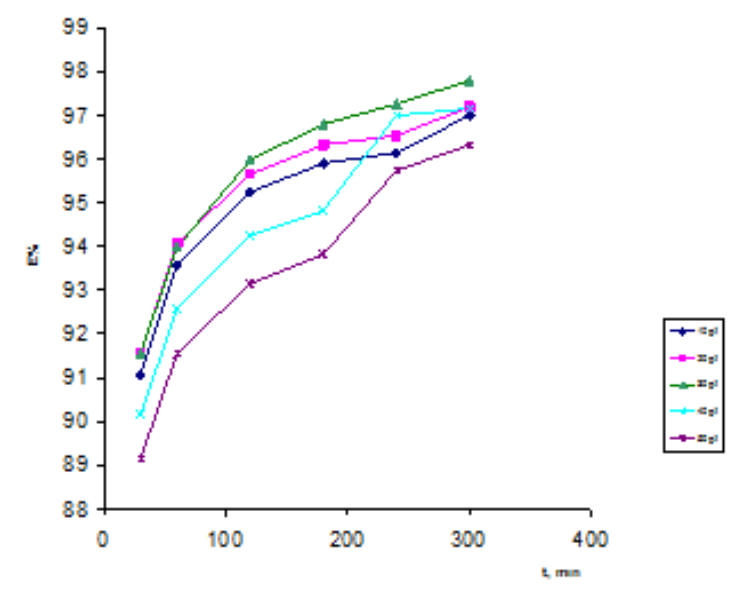

Fig. 3: Removal efficiency of $\mathrm{PKN}$ activated with $\mathrm{NH}_{4} \mathrm{Cl} \mathrm{H}_{2} \mathrm{SO}_{4}$ 


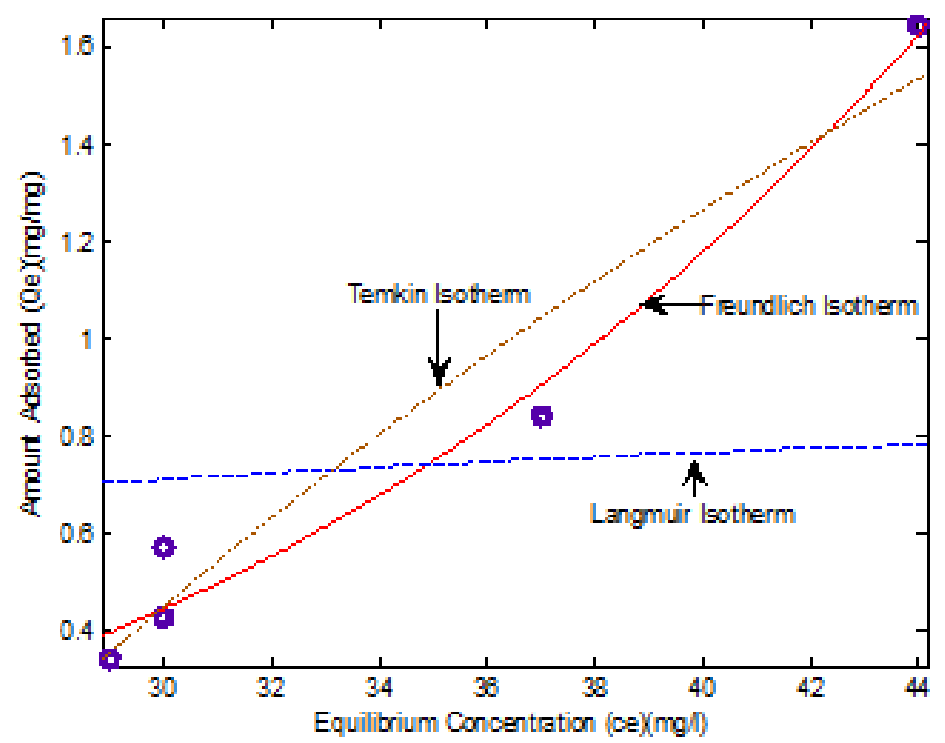

Fig. 4: Isotherm plot for fit to PKN activated with at different adsorbent concentration

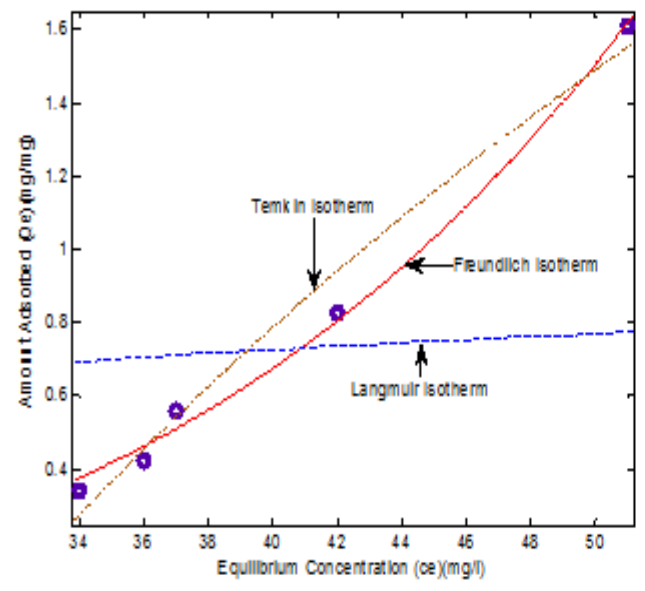

Fig.5: Isothermplot for fit to PKN activated with $\mathrm{Al}_{2}\left(\mathrm{SO}_{4}\right)_{3}$

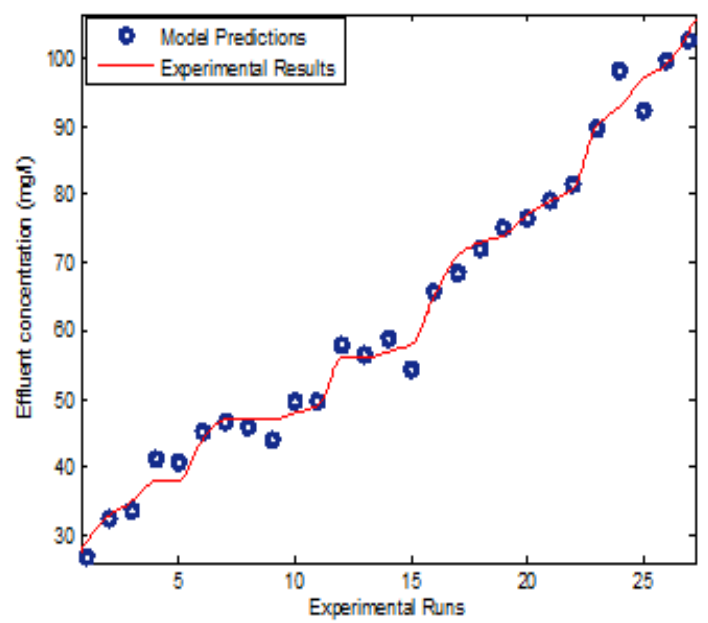

Fig.7: Experimental vs. Model Predictions for PKN activated with $\mathrm{H}_{2} \mathrm{SO}_{4}$

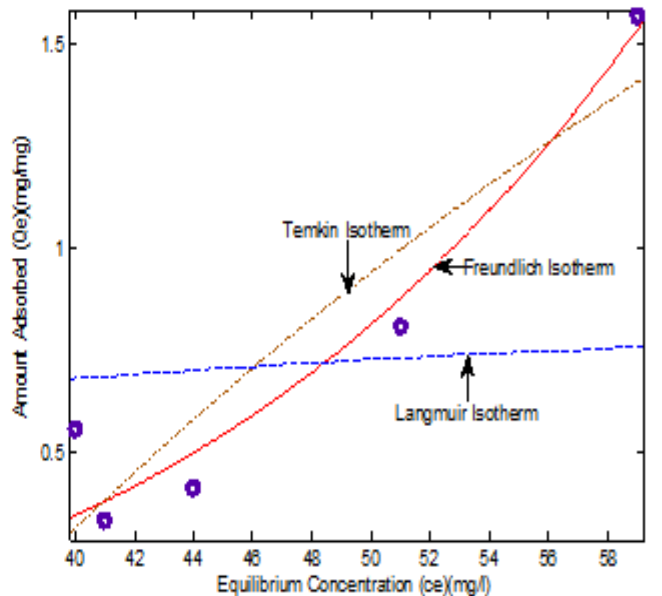

Fig.6: Isotherm plot for fit to $\mathrm{PKN}$ activated with $\mathrm{NH}_{4} \mathrm{Cl}$

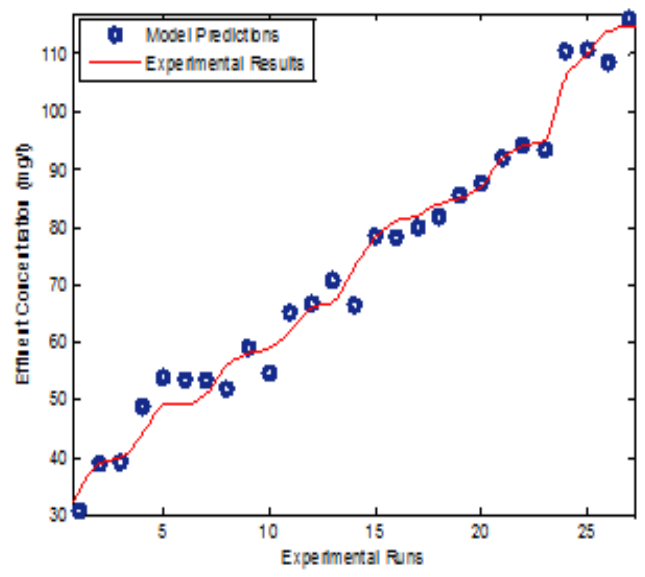

Fig.8: Experimental vs. Model Predictions for PKN activated with $\mathrm{Al}_{2}\left(\mathrm{SO}_{4}\right)_{3}$ 


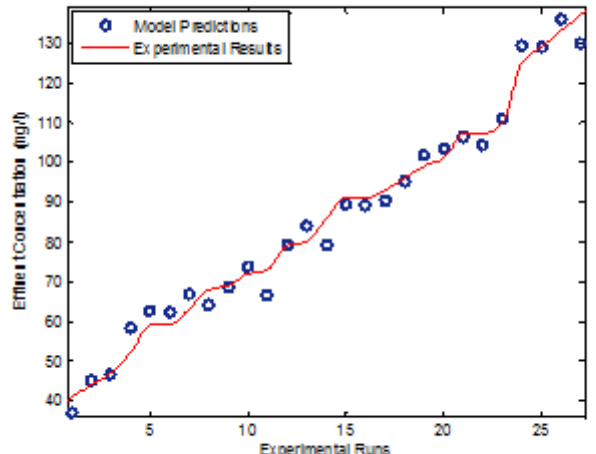

Fig. 9: Experimental vs. Model Predictions for PKN activated with $\mathrm{NH}_{4} \mathrm{Cl}$

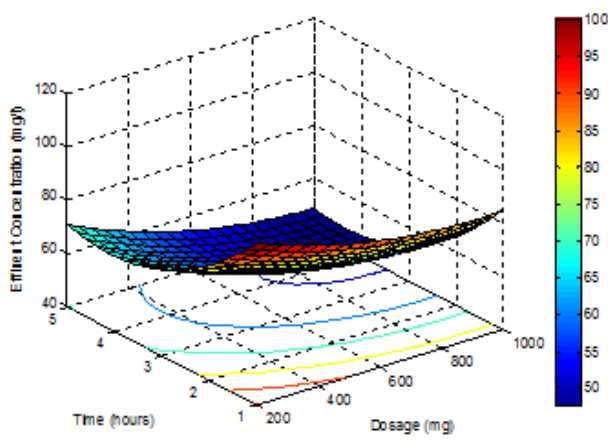

Fig. 11: 3-D Surface response Plot for PKN activated with $\mathrm{Al}_{2}\left(\mathrm{SO}_{4}\right)$

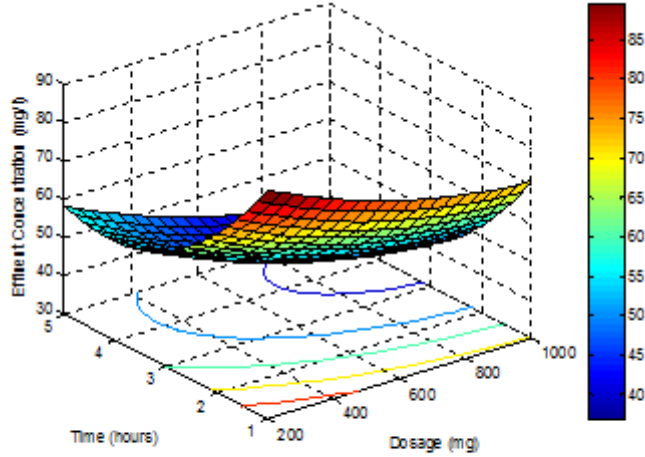

Fig. 10: 3-D Surface response Plot for PKN activated with $\mathrm{H}_{2} \mathrm{SO}_{4}$

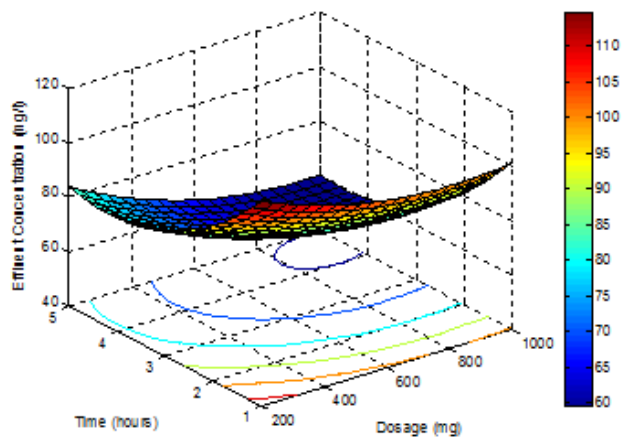

Fig. 12: 3-D Surface response Plot for PKN activated with $\mathrm{NH}_{4} \mathrm{Cl}$ 